\title{
Self-medication and homeostatic behaviour in herbivores: learning about the benefits of nature's pharmacy
}

\author{
J. J. Villalba ${ }^{\dagger}$ and F. D. Provenza \\ Department of Wildland Resources, Utah State University, Logan, Utah, USA
}

(Received 5 January 2007; Accepted 19 March 2007)

\begin{abstract}
Traditional production systems have viewed animals as homogeneous 'machines' whose nutritional and medicinal needs must be provided in a prescribed manner. This view arose from the lack of belief in the wisdom of the body to meet its physiological needs. Is it possible for herbivores to select diets that meet their needs for nutrients and to write their own prescriptions? Our research suggests it is. Herbivores adapt to the variability of the external environment and to their changing internal needs not only by generating homeostatic physiological responses, but also by operating in the external environment. Under this view, food selection is interpreted as the quest for substances in the external environment that provide homeostatic utility to the internal environment. Most natural landscapes are diverse mixes of plant species that are literally nutrition centres and pharmacies with vast arrays of primary (nutrient) and secondary (pharmaceutical) compounds vital in the nutrition and health of plants and herbivores. Plant-derived alkaloids, terpenes, sesquiterpene lactones and phenolics can benefit herbivores by, for instance, combating internal parasites, controlling populations of fungi and bacteria, and enhancing nutrition. Regrettably, the simplification of agricultural systems to accommodate inexpensive, rapid livestock production, coupled with a view of secondary compounds as toxins, has resulted in selecting for a biochemical balance in forages favouring primary (mainly energy) and nearly eliminating secondary compounds. There is a global need to create a more sustainable agriculture, with less dependence on external finite resources, such as fossil fuels and their environmentally detrimental derivatives. Self-medication has the potential to facilitate the design of sustainable grazing systems to improve the quality of land as well as the health and welfare of animals. Understanding foraging as the dynamic quest to achieve homeostasis will lead to implementing management programs where herbivores have access not only to diverse and nutritious foods but also to arrays of medicinal plants.
\end{abstract}

Keywords: behavioural homeostasis, foraging behaviour, learning, parasite control, self-medication

\section{Internal environment and homeostasis}

Claude Bernard (1865) introduced the idea of internal environment-internal milieu, as the fluid compartment within which cells of organs and tissues are bathed. This was a critical concept in physiology since it recognised the need of organisms to maintain an internal state protected from the variability and unpredictability of the external environment. The evolution of the 'constancy of the internal milieu' has been an essential factor that allowed animals to survive and thrive in changing environments.

The need to achieve a hospitable environment where cells and organs can perform in an optimal fashion was attributed to the continuous engagement at all levels cells, organs, individuals - in active self-preservation. The concept of organisms adapting and coping with their

\footnotetext{
${ }^{\dagger}$ E-mail: villalba@cc.usu.edu
}

environment was expanded and taken to a new dimension with the work of Cannon (1929). He coined the term 'homeostasis' to refer to all the complex and coordinated physiological processes that maintain steady states in organisms. The term 'homeostatic regulation' was then created to define and describe all those physiological processes and mechanisms that keep the body 'in balance'. Cannon argued that the body knows what is best - the wisdom of the body - and that organisms have 'ancient biological knowledge' embodied in their tissues (Schulkin, 2001 and 2005).

\section{Behavioural homeostasis}

Curt Richter extended Bernard's ideas on the constancy of the internal milieu and Cannon's views on homeostatic regulation by demonstrating the role of behaviour in the 
regulation of the internal environment (Schulkin, 2005). Richter realised that the body adapts to external circumstances and internal needs not only by generating physiological responses that correct deviations from steady states, but also by generating behaviours. The central idea of behavioural homeostasis is that behaviours also evolved to serve physiological regulation, bringing the concept of homeostasis into the realm of behaviour and psychology (Schulkin, 2005).

Richter's research showed that adrenalectomised rats, experiencing severe depletions of $\mathrm{Na}$, increased their intake and appetite for $\mathrm{NaCl}$ relative to control animals, behaviours that contributed substantially to their survival (Richter, 1936). His groundbreaking findings on the relationships between behaviour and homeostasis led him to argue that specific appetites could be used as a measure of physiological deficiencies or nutritional needs in animals. In general, Richter assumed that the animals' behavioural adjustments were innately programmed and guided by the sense of taste. In many aspects, he generalised his studies of sodium hunger to other specific hungers (Rozin, 1976).

The sodium model of nutritional wisdom was extrapolated to livestock by scientists attempting to explore 'instinctive appetites' for other nutrients. However, these efforts made researchers doubt that livestock possessed nutritional wisdom. Cattle and sheep did not instinctively ingest recommended levels of minerals, and many times animals' under- or over-consumed mineral supplements relative to their requirements (Coppock, 1970; Coppock et al., 1976; Pamp et al., 1977).

The idea of animals instinctively searching for specific substances in the environment in order to rectify their needs has also influenced ecological theory where food selection has been explained through a 'genetic programming of ingestive behaviour' (Schmidt-Nielsen, 1994). Evolution of foraging strategies that optimise nutrient intake (Belovsky, 1978; Stephens and Krebs, 1986) and fixed rules of thumb such as 'eat tall green grass' or 'avoid bitter' have also been proposed as mechanisms underlying diet selection in herbivores (Cassini, 1994). However, the 'sodium model of nutritional wisdom' is not a particularly good exemplar for energy, protein, minerals and vitamins because animals do not instinctively recognise through oduor/taste all of these nutrients, nor do they necessarily recognise all of the various configurations of any particular nutrient (Provenza and Balph, 1990; Provenza and Villalba, 2006). Beyond the evolution of fixed codes or static rules of thumb, animals evolved learning mechanisms to cope with the frequent changes occurring in the internal and external environment. Learning is itself a genetically evolved mechanism, a kind of fixed plasticity that, like evolution, is adaptive (Skinner, 1984). Collectively, the information presented in this paper supports the notion that behavioural regulation is an important way individuals achieve homeostasis. However, needs are not fixed and neither are the behaviours underlying homeostatic regulation fixed or pre-programmed; they have a significant learned component. Behaviours are flexible and a function of their consequences (Skinner, 1981).

\section{Feedback systems: a dynamic loop to learn based on consequences}

Homeostatic regulation involves a mechanism of control with precise monitoring and effector systems such that the condition of the internal environment is regulated within rather narrow limits. Such a system of control can be understood as a feedback loop, or a circular arrangement of functionally connected links. These links interact until the last link in the loop feeds back to the first link in the cycle, resulting in self-regulation of the system. Feedback is a dynamic control system that influences behaviour through actual, rather than expected performance (Capra, 1996). This monitoring-action loop is particularly relevant in living organisms because homeostasis is not static but inherently dynamic: set points, equilibrium states and biochemical processes change through time as organisms develop and preserve their integrity (Rose, 1998). Thus, feedback cycles do more than simply maintain variables within normal limits; they increase the flexibility and adaptability of a system's response (Provenza et al., 1998; Provenza and Villalba, 2006).

The first link of a feedback system in the food selection process can be depicted as signals from nutrients and toxins that originate in the external environment and upon food ingestion impact cellular receptors in the animal (Figure 1). These signals are conducted through afferent nerves to a selector or decision-making organ - the central nervous system - where information is processed, integrated and where an output - a decision - is produced. The decision is conducted through efferent nerves to an effector organ, a muscle or group of muscles, which allows the animal to operate on the environment (Figure 1). As a function of the behaviour performed by the animal, a new signal will now interact with the receptor system. Thus, by the recursive application of these simple rules the system 'rejuvenates' itself and updates constantly, creating new decisions and fine-tuning new behaviours until homeostasis is achieved. This plasticity implies that as signals - in either the internal or external environment - change in the short (e.g. within a meal) or long (e.g. months) term, responses will track such changes, always with the same final goal: homeostatic regulation.

\section{Homeostatic behaviour and diet selection}

Food preferences involve interactions between taste and postingestive feedback, which are determined by an animal's physiological condition and the food's chemical characteristics (Provenza, 1995 and 1996). The senses of smell and taste enable animals to discriminate among foods. Postingestive feedback calibrates sensory experiences of food - like or dislike - with its homeostatic utility. 


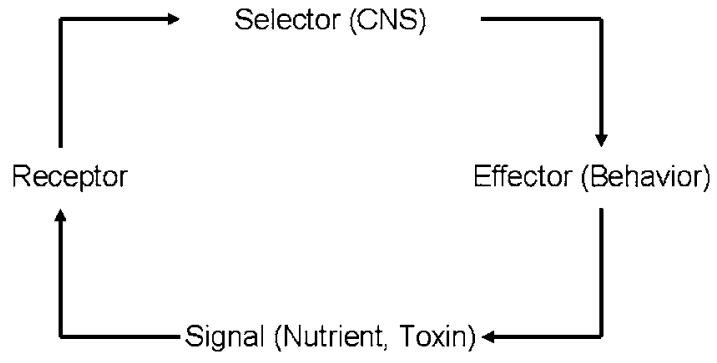

Figure $1 \mathrm{~A}$ feedback loop underlying behavioural homeostasis in herbivores. Feedback confers plasticity and adaptability to a system because control depends on actual conditions rather than on expected or predetermined performance. The recursive application of simple rules across each link of the loop rejuvenates and updates the system constantly, creating and fine-tuning behaviours until homeostasis is achieved.

Thus, the receptor systems of the animal involves sensory receptors in the nose and mouth - that allow for food discrimination - and visceral receptors that respond to nutrients, toxins, osmosis and pressure, which inform the selector system of the animal (central nervous system) about the consequences of ingesting food (Figure 1) (Provenza, 1995 and 1996; Provenza and Villalba, 2006)

Homeostatic behaviour can be observed in livestock fed diets that vary in nutrients. For instance, lambs and goats fed diets low in energy and protein prefer flavoured lowquality foods previously paired with intra-ruminal infusions of energy (starch, propionate, acetate) or nitrogen (urea, casein, gluten), respectively (Villalba and Provenza, 1996, 1997a, b and c; Arsenos et al., 2000; Duncan and Young, 2002). Given pre-loads of energy or nitrogen, lambs prefer flavours previously paired with nitrogen or energy, respectively, during the ensuing meals (Villalba and Provenza, 1999). Thus, animals maintain a balance of energy to protein that meets their nutritional needs, and in the process, they associate different internal states with the ingestion, or lack thereof, of different nutrients (Egan, 1980; Kyriazakis and Oldham, 1993). Likewise, lambs deficient in phosphorus and calcium increase preferences for flavours and supplements that provide those minerals (Villalba et al., 2006a; J. Villalba, unpublished results).

Homeostatic behaviour can be also observed when animals are offered diets with deficits or excesses of nutrients or excesses of toxins that deviate cells and organs from well-being and self-preservation. In this case, behaviours are geared towards limiting food intake. For instance, sheep are reluctant to eat poorly nutritious foods such as straw as straw does not meet needs for energy or protein, but their intake and preference for straw increase when a nutritious food (Greenhalgh and Reid, 1971) or starch (Villalba and Provenza, 1997a and 2000) is infused into the rumen immediately after a meal of straw. Ruminants also avoid flavours associated with excesses of nitrogen (Kyriazakis and Oldham, 1993; Villalba and Provenza, 1997a) or excesses of volatile fatty acids (Villalba and Provenza, 1997b) and limit intakes of otherwise nutritious foods that contain plant secondary metabolites (PSMs) (Provenza et al., 1990; Provenza, 1996; Dearing et al., 2005).

\section{Self-medication}

If herbivores can evolve mechanisms to maintain homeostasis and contemporarily learn to avoid certain foods because they lower their fitness, or prefer flavours associated with nutrients because they increase their fitness, they may also learn to ingest other substances in the environment such as medicines as they also raise fitness (Janzen, 1978). Just as foraging behaviour is influenced by nutrients and PSMs, some responses may also be geared towards reducing disease (Lozano, 1998).

Our thesis is that food selection in herbivores can be interpreted as the constant quest for substances in the external environment that provide a homeostatic benefit to the internal environment (Provenza and Villalba, 2006). Under this view, nutrients, PSMs, medicines are all 'substances' with the same final utility: improving the welfare of cells and cellular processes that enable life. Thus, selfmedication - as ingestion of nutrients and avoidance of PSMs - is another dimension of homeostatic behaviour in animals. Ingesting nutrients and medicines are means to the same end - stay well (Engel, 2002).

From prehistoric times, man has looked to the presumed self-medicative behaviour of animals for clues about remedies for ailments (Huffman, 2003). Implications of selfmedication transcend animal species and range from providing shortcuts for discovering new medicines (Clayton and Wolfe, 1993) to managing the well-being of wild and domestic animals (Lozano, 1998) and improving human health (Engel, 2002).

The study of self-medication in animals has led to the emergence of a new field, often referred to as 'zoopharmacognosy' to describe the process by which animals select and use PSMs or other non-nutritional substances for treating and preventing disease (Rodriguez and Wrangham, 1993). While little is known about the abilities of animals to self-medicate, and many of the observations are anecdotal and equivocal (Clayton and Wolfe, 1993; Lozano, 1998; Houston et al., 2001), there is evidence animals self-medicate (Engel, 2002). Researchers who contend that animals self-medicate under natural conditions do so based on observations that sick animals seek substances - not part of their normal diet and preferably with no nutritional benefit - that contain active ingredients capable of improving health (Ketch et al., 2001; Engel, 2002; Huffman, 2003). Such correlative studies are consistent with the self-medication hypothesis, but they do not establish cause and effect (Lozano, 1998).

The amount of detailed information on self-medication in animals available thus far is greatest in primates, in particular the African great apes (Huffman, 2003). The hypothesis from research on these animals is that self-medication behaviour aids in the control of internal parasites and 
provides relief from gastro-intestinal upset (Huffman, 2003; Huffman et al., 1993). Studies of apes show correlations between the occurrence of parasite loads and ingestion of anti-parasitic plant secondary compounds or plant parts that enhance mechanical expulsion (Huffman, 2001; Huffman and Caton, 2001).

One of the best examples of self-medication comes from observations that wild chimpanzees consume the bitter pith of the plant Vernonia amygdalina when suffering from parasite-related diseases even when $V$. amygdalina is not part of the animals' diet, despite its year-round availability. Parasite loads decrease dramatically after animals consume that plant, and overt signs of disease disappear (Huffman and Seifu, 1989; Huffman et al., 1993). V. amygdalina contains sesquiterpene lactones and steroid glucosides with antiparasitic activity at the doses consumed by the animals (Koshimizu et al., 1994; Ohigashi et al., 1994). PSMs in $V$. amygdalina also have been effective at controlling nematodes that cause significant losses of livestock in the tropics (Plotkin, 2000). Other plants selected by chimpanzees have medicinal effects in the amounts (doses) consumed: limonoids in Trichilia rubescens have antimalarial activity (Krief et al., 2004), and methoxypsoralen in Ficus exasperata is a strong antibiotic (Rodriguez and Wrangham, 1993).

\section{Beyond the African great apes: self-medication in livestock and other animals}

The most attractive and conspicuous animals, and those thought to be most similar to humans, have received the greatest attention regarding self-medication (e.g. African great apes; Huffman, 2003). However, evidence of selfmedication in primates may well represent an artifact of collection in as much as intensive research in a reduced number of species may suggest other species are unable to self-medicate (Plotkin, 2000). Nevertheless, there is evidence of self-medication in other animals including bears, geese, leopards and dogs (Huffman, 1997 and 2006). Asian two-horned rhinos consume large amounts of tannin-rich plants with antiparasitic properties (Janzen, 1978). Peruvian parrots prefer soils with much higher cation-exchange capacity than adjacent bands of rejected soils. Selected soils contain kaolin and mica, which bind PSMs such as alkaloids and tannic acid (Gilardi et al., 1999), allowing for increased diet breadth and digestibility. Likewise, some propose soil (35\% kaolin) consumption by African elephants assists in the digestion of browse by detoxifying high concentrations of PSMs in tropical forest trees (Houston et al., 2001).

Sheep learn to ingest medicines such as polyethylene glycol (PEG), a substance that attenuates the aversive effects of tannins, when they eat foods high in tannins, and they titrate the dose of PEG in accord with the amount of tannin in their diet (Provenza et al., 2000). They discriminate the medicinal benefits of PEG from non-medicinal substances by selectively ingesting PEG after eating a meal high in tannins (Villalba and Provenza, 2001). Sheep also choose to forage in locations where PEG is present when offered nutritious foods high in tannins in different locations. In contrast, time spent at locations with PEG declined when tannins were not present in their diets (Villalba and Provenza, 2002). Sheep fed acid-producing substrates such as grains subsequently ingest foods and solutions that contain sodium bicarbonate, which attenuates acidosis (Phy and Provenza, 1998). In the most elaborate studies to date, sheep learned to selectively ingest three medicines sodium bentonite, PEG, dicalcium phosphate - that lead to recovery from illness due to eating too high amounts of grain, tannins and oxalic acid, respectively (Villalba et al., 2006b). In contrast, control lambs that ate the same foods and medicines, but disassociated temporally so they did not recuperate from illness, never changed their pattern of use of the medicines, regardless of the food consumed before the choice of medicines. This study showed learning is a critical mechanism in self-medication and that sheep are able to form multiple malaise-medicine associations (Villalba et al., 2006b).

\section{Self-medication and plant secondary metabolites}

We have learned much during the past 30 years about the importance of PSMs in the health of plants, including functions as diverse as attracting pollinators and seed dispersers, helping plants recover from injury, protecting plants from ultraviolet radiation and defending plants against diseases, pathogens and herbivores (Rosenthal and Janzen, 1979; Palo and Robbins, 1991). PSMs cause postingestive consequences in herbivores typically through their negative actions on several cellular and metabolic processes, promoting reduced intake, weight loss and even death (Cheeke and Scull, 1985; Cheeke, 1998). Consequently, PSMs can exert some of those negative actions across several trophic levels, including herbivores and the bacteria, parasites and fungi that inhabit herbivores' bodies and cause decreases in health (Lozano, 1998). What has not been seriously considered in the ecological literature is that the difference between a toxin and a medicine can be very small, merely a matter of dosage (Plotkin, 2000).

Plant-derived alkaloids, terpenes and phenolics have antiparasitic properties (Kayser et al., 2003; Hocquemiller et al., 1991) and sesquiterpene lactones have antitumorigenic, anti-amoebic, anti-bacterial, anti-fungal and cardiotonic properties (Picman, 1986; Robles et al., 1995; Huffman et al., 1998). Thus, PSMs at appropriate doses have the potential to benefit herbivores in ways that may be more consequential than their negative effects. Nevertheless, the notion of herbivores using PSMs as medicines has been overshadowed by the inherent negative effects of PSMs at high doses on herbivores. Another constraint on using PSMs as medicines is the potential large quantities of a single PSM such as tannins required to achieve meaningful doses in the herbivore in order to combat disease (Waghorn and McNabb, 2003). 


\section{Self-medication and internal parasites}

Internal parasites are one of the greatest disease problems in grazing livestock worldwide (Min and Hart, 2003; Waller, 2006). Parasitism is often the most pervasive challenge to host survival and reproduction (Hutchings et al., 2003) and failure to control gastro-intestinal nematodes results in poor growth rates, ill thrift and death (Min et al., 2004). Nevertheless, control of internal parasites is not easy, particularly in recent times due to the rise of drug-resistant organisms (Plotkin, 2000; Jackson and Miller, 2006). Drugs used to control gastro-intestinal parasites are failing due to the increased prevalence of parasite resistance to anthelmintics (Pomroy et al., 2002; Min et al., 2004). Drug resistance is testimony to the remarkable biological plasticity of nematode parasites in response to a sustained and almost exclusive reliance on specific chemicals for disease control (Waller, 2006). More effective and sustainable programmes for combating parasites may be possible if more choices and the greater variety of controls, including anthelmintics, are used in combinations, along with grazing management designed to minimise parasite infections (Waller, 2006). Avoidance of dung patches and rotation of animals in landscapes probably occurred naturally, prior to the use of fencing in grazing management. Clearly, programmes that integrate grazing management and biological control, in addition to anthelmintics, are best for reducing parasites and minimising harmful effects of drugs on the functioning of soils (Strong, 1993; Floate et al., 2002).

Considerable attention has been given recently to bioactive plants that affect internal parasite populations (Jackson and Miller, 2006). Several in vitro and in vivo studies suggest condensed tannins have anthelmintic effects against ruminant nematode parasites. Livestock feeding on plants with tannins such as sulla (Hedysarum corarium) and sericea lespedeza (Lespedeza cuneata) have lower nematode burdens and lower faecal egg counts than those eating plants of similar quality without tannins (Niezen et al., 1998; Coop and Kyriazakis, 2001; Min and Hart, 2003; Min et al., 2004). Chicory (Cichorium intybus) contains an array of condensed tannins and other phenolic compounds including sesquiterpene lactones, coumarin and caffeic acid derivatives that reduce the need for commercial anthelmintics in young farmed deer (Hoskin et al., 1999).

The effectiveness of certain PSMs at combating disease has enhanced the interest in continuing the search for plants with therapeutic properties. The quest for bioactive PSMs in nature i.e. bioprospecting is the means that leads to two different ends: (1) the industrial approach, where the quest for bioactives has the main objective of creating new drugs and additives to combat disease and (2) the holistic and more sustainable approach where a variety of plants rich in PSMs or other bioactives are considered and incorporated into grazing systems for disease control (see also Athanasiadou and Kyriazakis, 2004). We believe that selfmedication has its highest potential for improving animal health and welfare under the sustainable approach.
If parasitised herbivores learn to self-medicate, given a variety of plant species with a variety of PSMs, producers may not need to give fixed or average dosages of chemicals to all the animals of a herd, likely with different parasite burdens, and it may not be necessary to force parasited animals to graze monocultures of PSM-rich pastures, which may lead to overconsumption of PSMs and to negative impacts on health and welfare. On the contrary, forage mixes could be sown to enhance the antiparasitic and nutritional characteristics of the forage on offer. If parasited animals learn to self-medicate on PSM-containing plants, this could aid in developing management programmes geared to seeding and distributing 'medicinal' plant species strategically in the environment, allowing herbivores to combat disease by themselves.

Use of anthelmintics as a function of need via selfmedication is a targeted treatment that reduces usage and helps maintain populations in refugia, which in turn aids in conserving the genes for susceptibility within parasite populations (Jackson and Miller, 2006). In fact, minimising treatment to periods of peak infection, rotating or combining different chemotherapies and proper dosage are fundamental principles to control for parasite chemoresistance in livestock and human treatment programmes (Geertz et al., 1997). Self-medicative behaviour in the African great apes appears to mirror these principles and may represent a stable evolutionary strategy for parasite control (Huffman et al., 1998). Thus, research on selfmedication may provide novel insights into strategies for countering the increased prevalence of parasite resistance to anthelmintics (Huffman et al., 1998). Moreover, selfmedication could be used in combination with other sustainable disease prevention and treatment practices such as nutritional and biological control and grazing management (Waller, 2006), and when necessary, with the conventional approach of drug application.

Even when self-medication may represent an effective and alternative tool for disease control, there is no evidence that livestock self-medicate to control infectious diseases (e.g. helminthoses) and information on livestock selfmedicating in general is limited. Thus, innovative and multidisciplinary research is needed to further explore the limits and variables of this behaviour in domestic animal species. This will help strengthen the current correlational evidence on self-medication and infectious diseases, providing a starting point for developing parasite control strategies in livestock systems.

\section{The fundamental dichotomy in self-medicating with PSMs: benefits $v$. costs}

\section{Overcoming the negative impacts of PSMs to experience} their benefits

The anti-parasitic, anti-fungal and anti-bacterial characteristics of PSMs come with a cost. This is because some of the negative impacts of PSMs on the cells and physiological processes of the disease-inducing agents also can adversely 
affect the host. Thus, the potential benefits associated with consuming PSMs by sick animals must be traded-off against the potentially negative consequences of PSMs on cells and physiological processes of the host (Hutchings et al., 2003).

The positive (medicine) and negative (toxic) effects of PSMs must be evaluated under the context of a common measure to determine the net positive or negative outcome of PSMs on herbivores. Animal performance emerges as an interesting possibility in this regard as both disease and PSM consumption affect performance (Athanasiadou and Kyriazakis, 2004). Athanasiadou and Kyriazakis (2004) propose three scenarios regarding the costs on herbivore performance from ingesting PSMs: (1) the negative impacts of PSMs overshadow their medicinal benefits; (2) the benefits of PSMs overshadow their anti-nutritional properties; and (3) the negative effects of PSMs offset their potential medicinal benefits. Beyond production costs and benefits, the crucial question for understanding selfmedication with PSMs is: can sick herbivores associate a potential medicinal effect with PSMs they might otherwise avoid (Engel, 2002; Hutchings et al., 2003) and under what circumstances will herbivores ingest PSMs to experience the benefits?

Typically, PSMs decrease preference for food, a mechanism that prevents herbivores from exceeding their capacity to biotransform and eliminate these compounds, which in turn prevents toxicosis (Provenza, 1996). Aversions result from the stimulation of the emetic system of the midbrain and brain stem (Mitchelson, 1992). Stimulation of this system induces malaise, and subsequently causes the animal to decrease intake of food (Provenza, 1996). Based on this mechanism we can depict a cost-benefit scenario within the realm of self-medication (Figure 2).
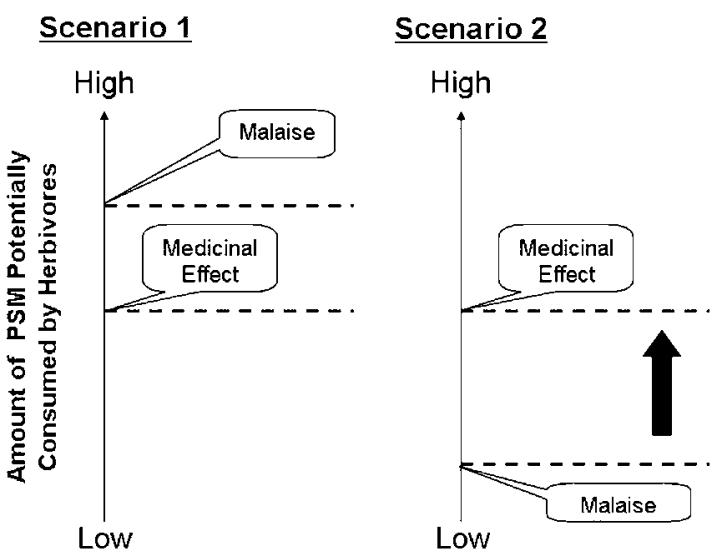

Figure 2 Two potential scenarios affecting the likelihood of learning about the beneficial effects of plant secondary metabolites (PSMs). In the first scenario, the dose needed for PSMs to have a medicinal effect requires that the animal ingest amounts of PSMs that are below those that cause malaise and stimulation of the emetic centre. In this scenario, the likelihood of animals being willing to consume therapeutical amounts of PSMs will be high. In contrast, in the second scenario the dose needed for PSMs to have a medicinal effect requires that the animal eats amounts of PSMs which are above those that cause malaise and stimulation of the emetic centre. This hierarchy of malaise and medicinal effects may prevent herbivores from learning about the beneficial effects of PSMs.
If the amount of PSM required to induce a therapeutic effect in herbivores is below the threshold amount that causes malaise and stimulates the emetic system, then the likelihood of animals consuming such amounts to selfmedicate and combat disease will increase. In turn, ingestion of PSMs will give sick herbivores the opportunity to experience the therapeutic effects of PSMs, which may lead to a stronger preference for such compounds. In contrast, if the doses of PSM required to promote a medicinal effect are equal or above the threshold amount that stimulates the emetic system, then the likelihood of animals crossing such a threshold will diminish (Figure 2). Low or no therapeutic consumption of PSMs will deprive animals from experiencing the potential medicinal benefits of PSMs. However, if animals are forced to cross the 'malaise threshold' and experience the benefits of consuming PSMs, will they subsequently select PSMs to combat disease when they are not forced to do so? Will they subsequently cross the 'malaise threshold' by themselves?

Previous research suggests they might. Lambs in a group (experienced) were forced to consume foods with tannins, terpenes and oxalates. These foods are complementary as the combined intake of the three foods is comparable with the intake of food without PSMs (Villalba et al., 2004). A second group of lambs (naïve) was not forced to consume the PSM-containing foods. Subsequently, when these foods were offered in a choice, lambs with experience ate significantly more of the foods containing the PSMs, up to $40 \%$ of their diet, even when safe and nutritious foods (alfalfa, barley) were available ad libitum. These differences in food preferences and intake persisted during trials a year later (Villalba et al., 2004).

Up to this point, we have considered animals ingesting large doses of PSMs to obtain medicinal benefits, but animals may not need to ingest PSMs in amounts that stimulate the emetic system. Consuming small amounts of a variety of PSMs, below therapeutic doses but on a daily basis, may have a cumulative effect that eventually will negatively impact disease-inducing organisms such as parasites (F. Jackson, personal communication). Preliminary results in our laboratory suggest low amounts of quebracho tannin consumed by lambs on a daily basis have negative impacts on nematode faecal egg counts (L. Lisonbee et al., unpublished results).

Some propose herbivores have evolved specific changes in diet selection in response to parasitism (Kyriazakis et al., 1998), which may facilitate exposure and familiarity with PSMs in parasitised animals. Behaviour is a function of need (Provenza et al., 2003) and by sampling a variety of bitter substances an animal may increase the probability of finding an active compound that supplies a medicinal benefit (Freeland and Janzen, 1974; Glendinning, 1994). Given the chemoprophylactic effects of bitter-tasting substances such as tannins and sesquiterpene lactones discussed above, it is conceivable that herbivores benefit from consuming low doses of such compounds when sick. In support of this, parasitised sheep begin to sample novel 
low-quality foods with quebracho tannin more readily than non-parasitised animals (L. Lisonbee et al., unpublished results). Repeated sampling of a bitter-tasting antimalarial agent (chloroquine) by malaria-infected mice significantly reduced percentages of parasitemia and the risk of mortality (Vitazkova et al., 2001). More recently, a mechanism for increasing preference for PSMs when organisms are under parasitic burdens has been described. Infection by parasites alters the taste response for specific PSMs (pyrrolizidine alkaloids) in caterpillars, and in so doing, encourages PSM ingestion, providing a biochemical defence (Bernays and Singer, 2005). Finally, social models are likely to be another way herbivores are enticed to cross the 'malaise threshold' and become exposed to the beneficial effects of PSMs (see below).

\section{Self-medicating in chemically diverse environments: an alternative for reducing costs and enhancing benefits} In studies where production in parasitised animals has been recorded, performance remained the same or was impaired by the addition of PSMs to supplements of feeds. No net benefit in terms of production has been found (Athanasiadou and Kyriazakis, 2004). However, the majority of such studies have forced animals to consume PSMs and only a single PSM has been offered, much as conventional approaches use anthelmintic drugs.

Historically, we have emphasised monocultures of plants on pastures and even on rangelands (Provenza et al., 2007). We are just beginning to appreciate the importance of PSMs and biodiversity in the foraging behaviour of herbivores (Provenza and Villalba, 2006; Provenza et al., 2007). We believe creating mixtures of plants whose PSM profiles complement one another and allowing animals to selfmedicate using a diverse array of PSMs is the way to reduce the negative impacts of PSMs on animal production and to enhance animal health through the medicinal effects of PSMs.

All plants contain PSMs that limit the amount of a particular plant a herbivore can eat. Herbivores are able to meet their needs for nutrients by ingesting a variety of plants with different PSMs that complement one another (Freeland and Janzen, 1974; Provenza et al., 2003). Large doses of one PSM overload specific detoxification mechanisms in herbivores. Thus, PSMs that affect different organs or detoxification pathways are likely to be less toxic as a diluted mixture than as a larger dose of one PSM (Freeland and Janzen, 1974). Indeed, sheep eat more when offered choices of foods with various PSMs that affect different detoxification mechanisms, and thus are complementary (Burritt and Provenza, 2000; Villalba et al., 2004).

If animals can consume a higher total amount of PSMs that are detoxified by different detoxification pathways, then it is likely organisms inhabiting a host will receive a greater total dose of PSMs, making the effectiveness of the treatment greater. Thus, by providing a variety of plants with different PSM profiles, herbivores may be able to meet needs for nutrients and combat disease simultaneously.
Both bacterial resistance to drugs and the developing anthelmintic resistance to drugs show how strains of bacteria and parasites can quickly evolve to survive any one type of selection pressure (e.g. specific antibiotics and anthelmintics). Thus, they are also perfectly capable of doing the same with other chemicals (Waller, 2006), just as treatment with a single PSM such as tannins. A diversity of PSMs might provide the variability needed to prevent or diminish the development of resistance.

\section{Eating nutrients or PSMs?}

Given the negative impacts of PSMs and the positive effects of nutrients on a herbivore's physiology, a superficial analysis of the rules that guide foraging behaviour may lead to the conclusion that animals will strongly avoid PSMs and select nutrient-rich forages. However, not only do herbivores manifest partial preferences (Westoby, 1978), they also ingest substantial amounts of PSMs (Provenza, 1995 and 1996; Villalba et al., 2004), likely due in part to their health and medicinal effects. If we view nutrients from another angle, they can also enhance resilience and resistance of the host to disease (Coop and Kyriazakis, 1999 and 2001). For instance, protein intake increases the resilience of livestock to parasitic infection by increasing host productivity, and when protein bound to tannins bypasses the rumen and is subsequently digested in the small intestine, that protein enhances immunity to nematode infections (Coop and Kyriazakis, 2001; Ketzis et al., 2006). Thus, both nutrients and PSMs can supply 'health and medicinal' benefits to herbivores. The question is how grazing animals in their homeostatic quest for substances in their external environment can best harvest both the benefits of nutrients and PSMs, such that they achieve optimal nutrition and enhanced protection against disease.

A useful approach to dealing with the complexity of interactions among nutrients and PSMs in food selection is the 'geometric framework' or the state-space graphical representation of the animal within its chemical environment (Simpson and Raubenheimer, 1999; Raubenheimer and Simpson, 1997). A Cartesian coordinate system defines a 'chemical space' where each coordinate represents a specific chemical, such as a nutrient or a PSM. In this synthesis, there is a point in chemical space or a 'target' that represents the optimal intake of the chemicals in question relative to the animal's physiological state. The rationale of this system is rooted in behavioural homeostasis: When herbivores are offered choices among foods with different concentrations of nutrients and PSMs with medicinal properties, their selection should reflect the outcome of homeostatic regulation for the chemicals in question.

The trade-off between toxicity-nutrition-medicinal effects can be depicted in a two-dimensional space, where one dimension is a nutrient ('nutrient axis') and the other a PSM that provides medicinal effects ('PSM axis'). Each food available for consumption is represented in that space by a line or 'rail' as it contains a specific proportion of nutrients 


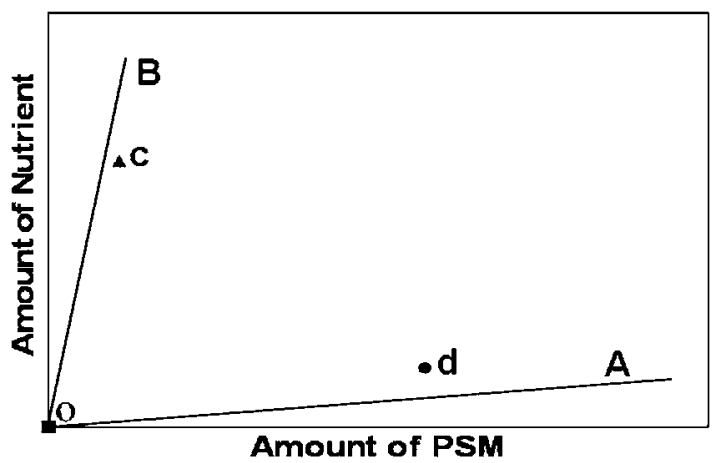

Figure 3 Schematic illustration of nutrient and plant secondary metabolite (PSM) regulation in a two-dimensional space. The line OA represents a food high in PSMs and low in nutrients (medicinal food), whereas the line OB represents a food low in PSMs and high in nutrients (nutritive food). The depicted points in space represent two possible outcomes of a selection made by a hypothetical animal when the two foods are available for consumption. The point ' $c$ ' represents a decision where the animal is not willing to consume high amounts of PSMs and thus selects almost exclusively the food high in nutrients. In contrast, the point ' $d$ ' represents a decision where the animal consumes substantial amounts of PSMs but low amounts of nutrients.

and PSMs. For instance, in Figure 3 the OA line represents a food high in PSMs and low in nutrients (e.g. medicinal food), whereas the $\mathrm{OB}$ line represents a food low in PSMs and high in nutrients (e.g. nutritive food). A point in chemical space represents the hypothetical choice made by animals when offered these two foods. The point closer to the nutritive food (' $c$ '; Figure 3) depicts a choice where the animal is not willing to consume high amounts of PSMs and thus prefers the nutritive food. On the other extreme, the point closer to the medicinal food ('d'; Figure 3) shows a choice where the animal consumes higher amounts of PSMs (i.e., is willing to 'take its medicine') to the detriment of its nutrition. Animals performing the former choice will consume their required nutrients but not enough PSMs, which may not be optimal if the animal is sick and the medicine is highly effective at combating disease. In contrast, the latter choice will provide doses for medicinal effects but not enough nutrients.

The challenge is for the animal to determine - once animals are trained to experience the beneficial effects of PSMs and nutrients from the foods on offer - the optimal point in chemical space to maintain homeostasis by meeting needs for nutrients and PSMs. For instance, animals with a parasitic burden may be willing to consume more pastures with bioactive PSMs that enhance health than non-parasitised animals. Parasitised animals may increase their grazing time to include medicinal plants in their diets. This analysis, beyond the theoretical implications for the interactions of nutrient-medicine, may guide the design of grazing systems where nutritive and medicinal plants are sown to deliver optimal proportions of nutrients and bioactive PSMs for animal nutrition and health.

\section{Trans-generational transmission of self-medication}

Social organisation creates culture, the knowledge and habits acquired by ancestors and passed from one generation to the next about how to survive in an environment (De Waal, 2001). Cultures develop when learned practices contribute to the group's success in solving problems. Cultures evolve as individuals in groups discover new ways of behaving, as with finding new foods or habitats and better ways to use foods and habitats (Skinner, 1981). The transition from the unfamiliar to the familiar begins at conception and in utero with mother and continues after birth with mother and peers. Lessons learned early in life from a mother create a dichotomy between the familiar and the unfamiliar (novel), which is essential for survival (Provenza, 1995; Provenza et al., 1998 and 2003). Animals prefer familiar to novel foods and environments and they prefer to be with companions as opposed to strangers (Provenza et al., 1998). Critically, animals are at the same time cautious and curious about the unfamiliar. Maintaining the appropriate balance between the two is critical for survival.

Socialising enhances learning efficiency because each animal no longer has to discover everything through trial and error. It is difficult for animals to learn through trial and error about the medicinal effects of substances, especially if behaviour and consequences (flavour-feedback) are not contingent (paired consistently) and contiguous (paired closely in time). Naïve animals familiar with only a limited number of foods in a landscape, or familiar with many foods eaten in the wrong sequence, may be less likely to learn about the potential medicinal values of foods available in their environment. Thus, 'pioneering' animals in a social group - those that learn exclusively based on consequences - must be positioned in the 'right place and at the right time'. Once an individual ingests the 'right foods at the right time' the beneficial effects of the new behaviour may then spread through the group, becoming part of the foraging behaviour of females (Huffman, 2001; Huffman and Hirata, 2004), who can then transmit those behaviours to their offspring.

Such transmission of information across generations occurs in livestock. For instance, when offered a choice, lambs avoid or prefer foods as a function of their mothers' avoidances or preferences (Mirza and Provenza, 1990 and 1992). When a mother's food selection behaviour (eat or avoid) is subsequently reinforced by postingestive feedback from nutrients or toxins (positive or negative), her offsprings respond strongly (eat or avoid) to a food (Provenza et al., 1993). Such knowledge then becomes a part of the culture, wherein young animals learn from their ancestors through their mothers. As mentioned above, mother and peers may facilitate exposure to PSMs in naïve animals, increasing the likelihood of experiencing the beneficial effects of PSMs, even when they have to be ingested at doses that cause stimulation of the emetic system.

\section{Conclusions and implications}

There is an increasing need to create a sustainable agriculture, with less dependence on external finite resources, such as fossil fuels and their environmentally detrimental 
derivatives. From the consumer perspective, there is also an increasing demand for products that are both 'clean' and 'green' (Waller, 2006).

Natural landscapes with diverse mixtures of plant species are literally nutrition centres and pharmacies with vast arrays of primary (nutrient) and secondary (pharmaceutical) compounds vital in the nutrition and health of plants and herbivores. Regrettably, the simplification of agricultural systems to accommodate inexpensive, rapid livestock production, coupled with a view of secondary compounds as toxins, has resulted in selecting for a biochemical balance in forages favouring primary (mainly energy) and nearly eliminating secondary compounds. Ironically, while we were minimising secondary compounds to maximise yields of crop and pasture plants over the past 30 years, we were learning of their value in plant resistance to environmental stressors, and we are now beginning to appreciate their nutritional and pharmaceutical values for herbivores and people. In their stead, we resorted to fertilisers, herbicides and insecticides to grow and protect plants in monocultures, and antibiotics and anthelmintics to maintain the health of herbivores.

Most contemporary agricultural systems have also viewed animals as 'machines' whose fuel - needed nutrients and medicines - had to be provided at prescribed times and known amounts. While more research is required, evidence presented in this paper suggests herbivores can meet their needs for nutrients and 'write their own prescriptions'. If so, self-medication by herbivores can contribute to sustainable grazing systems with benefits to the environment and to the animal's health and welfare.

Viewing foraging behaviour as the quest for substances in the external environment that provide homeostatic utility to the 'internal milieu' leads us to the conclusion that selfmedication is the consequence of the same mechanism that allows animals to form preferences for nutrients (Villalba and Provenza, 1996, 1997a, b, and c, 1999) and develop aversions to toxins (Provenza et al., 1990): Behaviour by consequences. Thus, while nutrients, PSMs and medicines are labels scientists use to better comprehend foraging complexity, for the animal in a dynamic homeostatic quest, ingesting nutrients, PSMs and medicines are means to the same end - staying well.

\section{Acknowledgements}

This effort was supported by grants from the Utah Agricultural Experiment Station and the Initiative for the Future of Agriculture and Food Systems, USDA. This paper is published with the approval of the Director, Utah Agricultural Experiment Station, and Utah State University, as journal paper number 7852. We thank A. Duncan and two anonymous reviewers for valuable comments to improve the manuscript.

\section{References}

Arsenos G, Kyriazakis I and Tolkamp BJ 2000. Conditioned feeding responses of sheep towards flavoured foods associated with the administration of ruminally degradable and/or undegradable protein sources. Animal Science 71, 597-606.
Athanasiadou S and Kyriazakis I 2004. Plant secondary metabolites: antiparasitic effects and their role in ruminant production systems. Proceedings of the Nutrition Society 63, 631-639.

Belovsky GE 1978. Diet optimization in a generalist herbivore: the moose. Theoretical Population Biology 14, 105-134.

Bernard C 1865. An introduction to the study of experimental medicine. Dover Publications 1957, New York.

Bernays EA and Singer MS 2005. Insect defences: taste alteration and endoparasites. Nature 436, 476.

Burritt EA and Provenza FD 2000. Role of toxins in intake of varied diets by sheep. Journal of Chemical Ecology 26, 1991-2005.

Cannon WB 1929. Bodily changes in pain, hunger, fear and rage, 2nd edition. Harper and Row, New York.

Capra F 1996. The web of life. Doubleday, New York.

Cassini MH 1994. Behavioral mechanisms of selection of diet components and their ecological implications in herbivorous mammals. Journal of Mammalogy 75, 733-740.

Cheeke PR 1998. Natural toxicants in feeds, forages, and poisonous plants. Interstate Publications Inc., Danville, IL, USA.

Cheeke PR and Shull LR 1985. Natural toxicants in feeds and poisonous plants. Avi Publishing Company Inc., Westport, CN, USA

Clayton DH and Wolfe ND 1993. The adaptive significance of self-medication. Trends in Ecology and Evolution 8, 60-63.

Floate KD, Colwell DD and Fox AS 2002. Reductions of non-pests insects in dung of cattle treated with endectocides: a comparison of four products. Bulletin of Entomological Research 92, 471-481.

Coop RL and Kyriazakis I 1999. Nutrition-parasite interaction. Veterinary Parasitology 84, 187-204.

Coop RL and Kyriazakis I 2001. Influence of host nutrition on the development and consequences of nematode parasitism in ruminants. Trends in Parasitology 17, 325-330.

Coppock CE. 1970. Free choice mineral consumption by dairy cattle. Proceedings of the Cornell nutrition conference, pp. 29-35.

Coppock CE, Everett RW and Belyea RL 1976. Effect of low calcium or low phosphorous diets on free choice consumption of dicalcium phosphate by lactating dairy cows. Journal of Dairy Science 59, 571-580.

Dearing MD, Foley WJ and McLean S 2005. The influence of plant secondary metabolites on the nutritional ecology of herbivorous terrestrial vertebrates. Annual Review of Ecology, Evolution, and Systematics 36, 169-189.

De Waal F 2001. The ape and the sushi master. Cultural reflections of a primatologist. Basic Books, New York.

Duncan AJ and Young SA 2002. Can goats learn about foods through conditioned food aversions and preferences when multiple food options are simultaneously available? Journal of Animal Science 80, 2091-2098.

Egan AR 1980. Host animal-rumen relationships. Proceedings of the Nutrition Society 39, 79-87.

Engel C 2002. Wild health. Houghton Mifflin Co., Boston, MA, USA.

Freeland WJ and Janzen DH 1974. Strategies in herbivory by mammals: the role of plant secondary compounds. American Naturalist 108, 269-286.

Geertz S, Coles GC and Gryseels B 1997. Anthelmintic resistance in human helminths: learning from the problems with worm control in livestock. Parasitology Today 13, 149-151.

Gilardi JD, Duffey SS, Munn CA and Tell LA 1999. Biochemical functions of geophagy in parrots: detoxification of dietary toxins and cytoprotective effects. Journal of Chemical Ecology 25, 897-922.

Glendinning Jl 1994. Is the bitter rejection response always adaptive? Physiology and Behaviour 56, 1217-1227.

Greenhalgh JFD and Reid GW 1971. Relative palatability to sheep of straw, hay and dried grass. British Journal of Nutrition 26, 107-116.

Hocquemiller R, Cortes D, Arango GJ, Myint SH, Cave A, Angelo A, Munoz V and Fournet A 1991. Isolation and synthesis of espintanol, a new antiparasitic monoterpene. Journal of Natural Products 54, 445-452.

Hoskin SO, Barry TN, Wilson PR, Charleston WAG and Hodgson J 1999. Effects of reducing anthelmintic input upon growth and faecal egg and larval counts in young farmed deer grazing chicory (Cichorium intybus) and perennial ryegrass 
(Lolium perenne)/white clover (Trifolium repens) pasture. Journal of Agricultural Science 132, 335-345.

Houston DC, Gilardi JD and Hall AJ 2001. Soil consumption by elephants might help to minimize the toxic effects of plant secondary compounds in forest browse. Mammal Reviews 31, 249-254.

Huffman MA 1997. Current evidence for self-medication in primates: a multidisciplinary perspective. American Journal of Physical Anthropology 104(Suppl. 25), 171-200.

Huffman MA 2001. Self-medicative behavior in the African great apes: an evolutionary perspective into the origins of human traditional medicine. BioScience 51, 651-661.

Huffman MA 2003. Animal self-medication and ethno-medicine: exploration and exploitation of the medicinal properties of plants. Proceedings of the Nutrition Society 62, 371-381.

Huffman MA 2006. Primate self-medication. In Primates in perspective (ed. C Campbell, A Fuentes, K MacKinnon, M Panger and S Bearder), pp. 677-689. University of Oxford Press, Oxford, UK.

Huffman MA and Seifu M 1989. Observations on the illness and consumption of a possibly medicinal plant Vernonia amygdalina by a wild chimpanzee in the Mahale Mountains National Park, Tanzania. Primates 30, 51-63.

Huffman MA and Caton JM 2001. Self-induced increase of gut motility and the control of parasitic infections in wild chimpanzees. International Journal of Primatology 22, 329-346.

Huffman MA and Hirata S 2004. An experimental study of leaf swallowing in captive chimpanzees: insights into the origin of a self-medicative behavior and the role of social learning. Primates 45, 113-118.

Huffman MA, Gotoh S, Izutso D, Koshimizu K and Kalunde MS 1993. Further observations on the use of Vernonia amygdalina by a wild chimpanzee, its possible effect on parasite load, and its phytochemistry. African Study Monographs 14, 227-240.

Huffman MA, Ohigashi H, Kawanaka M, Page JE, Kirby GC, Gasquet M, Murakami A and Koshimizu K 1998. African great ape self-medication: a new paradigm for treating parasite disease with natural medicines? In Towards natural medicine research in the 21st century (ed. H Ageta, N Aimi, Y Ebizuka, T Fujita and G Honda), pp. 113-123. Elsevier Science, Amsterdam, The Netherlands.

Hutchings MR, Athanasiadou S, Kyriazakis I and Gordon I 2003. Can animals use foraging behaviour to combat parasites? Proceedings of the Nutrition Society 62, 361-370.

Janzen J 1978. Complications in interpreting the chemical defenses of trees against tropical arboreal plant-eating vertebrates. In The ecology of arborea folivores (ed. G Montgomery), pp. 73-84. Smithsonian Institution Press, Washington, DC, USA.

Jackson F and Miller J 2006. Alternative approaches to control: quo vadit? Veterinary Parasitology 139, 371-384.

Kayser 0, Kiderlen AF and Croft SL 2003. Natural products as antiparasitic drugs. Parasitology Research 90 (suppl. 2), 55-62.

Ketch LA, Malloch D, Mahaney WC and Huffman MA 2001. Comparative microbial analysis and clay mineralogy of soils eaten by chimpanzees (Pan troglodytes schweinfurthii) in Tanzania. Soil Biology and Biochemistry 33, 199-203.

Ketzis JK, Vercruysse J, Stromberg BE, Larsen M, Athanasiadoum W and Houdijk JG 2006. Evaluation of efficacy expectations for novel and nonchemical helminth control strategies in ruminants. Veterinary Parasitology 139, 321-335.

Koshimizu K, Ohigashi H and Huffman MA 1994. Use of Vernonia amygdalina by wild chimpanzee: Possible roles of its bitter and related constituents. Physiology and Behaviour 56, 1209-1216.

Krief S, Martin MT, Grellier P, Kasenene J and Sevenet T 2004. Novel antimalarial compounds isolated in a survey of self-medicative behavior of wild chimpanzees in Uganda. Antimicrobiological Agents and Chemotherapy 48, 3196-3199.

Kyriazakis I and Oldham JD 1993. Diet selection in sheep: the ability of growing lambs to select a diet that meets their crude protein (nitrogen $\times 6.25$ ) requirements. British Journal of Nutrition 69, 617-629.

Kyriazakis I, Tolkamp BJ and Hutchings MR 1998. Towards a functional explanation for the occurrence of anorexia during parasitic infections. Animal Behaviour 56, 265-274.
Lozano GA 1998. Parasitic stress and self-medication in wild animals. In Advances in the study of behavior (ed. AP Moler, M Milinski and PJB Slater), vol. 27, pp. 291-317. Elsevier Science, London, UK.

Min BR and Hart SP 2003. Tannins for suppression of internal parasites. Journal of Animal Science 81, E102-E109.

Min BR, Pomroy WE, Hart SP and Sahlu T 2004. The effect of short-term consumption of a forage containing condensed tannins on gastro-intestinal nematode parasite infections in grazing wether goats. Small Ruminant Research 51, 279-283.

Mirza SN and Provenza FD 1990. Preference of the mother affects selection and avoidance of foods by lambs differing in age. Applied Animal Behaviour Science 28, 255-263.

Mirza SN and Provenza FD 1992. Effects of age and conditions of exposure on maternally mediated food selection by lambs. Applied Animal Behaviour Science 33, 35-42.

Mitchelson F 1992. Pharmacological agents affecting emesis. A review (part I). Drugs 43, 295-315.

Niezen JH, Robertson HA, Waghorn GC and Charleston WAG 1998. Production, faecal egg counts and worm burdens of ewe lambs which grazed six contrasting forages. Veterinary Parasitology 80, 15-27.

Ohigashi $H$, Huffman MA, Izutsu D, Koshimizu K, Kawanaka M, Sugiyama $H_{\text {, }}$ Kirby GC, Warhurst DC, Allen D, Wright CW, Phillipson JD, Timmon-David P, Delmas F, Elias R and Balansard G 1994. Toward the chemical ecology of medicinal plant use in chimpanzees: the case of Vernonia amygdalina, a plant used by wild chimpanzees possibly for parasite-related diseases. Journal of Chemical Ecology 20, 541-553.

Palo RT and Robbins CT 1991. Plant defenses against mammalian herbivory. CRC Press, Boca Raton, FL, USA.

Pamp DE, Goodrich RD and Meiske JC 1977. Free choice minerals for lambs fed calcium- or sulfur-deficient rations. Journal of Animal Science 45, 1458-1466. Phy TS and Provenza FD 1998. Sheep fed grain prefer foods and solutions that attenuate acidosis. Journal of Animal Science 76, 954-960.

Picman AK 1986. Biological activities of sesquiterpene lactones. Biochemistry Systematics and Ecology 14, 255-281.

Plotkin MJ 2000. Medicine quest. In search of nature's healing secrets. Penguin Putnam Inc., New York, NY, USA.

Pomroy WE, Hart SP and Min BR 2002. Tritration of efficacy of ivermectin and moxidectin against an ivermectin-resistant Haemonchous contortus derived from goats in the field. Journal of Animal Science 80 (suppl. 2), (abstr.), 30

Provenza FD 1995. Postingestive feedback as an elementary determinant of food preference and intake in ruminants. Journal of Range Management 48, 2-17.

Provenza FD 1996. Acquired aversions as the basis for varied diets of ruminants foraging on rangelands. Journal of Animal Science 74, 2010-2020.

Provenza FD and Balph DF 1990. Applicability of five diet-selection models to various foraging challenges ruminants encounters. In Behavioural mechanisms of food selection (ed. RN Hughes), NATO ASI series G: Ecological Sciences, vol. 20, pp. 423-459. Springer, Berlin, Heildelberg, Germany.

Provenza FD and Villalba JJ 2006. Foraging in domestic vertebrates: linking the internal and external milieu. In Feeding in domestic vertebrates: from structure to behaviour (ed. VL Bels), pp. 210-240. CABI Wallingford, Oxfordshire, UK.

Provenza FD, Burritt EA, Clausen TP, Bryant JP, Reichardt PB and Distel RA 1990. Conditioned flavor aversion: a mechanism for goats to avoid condensed tannins in blackbrush. American Naturalist 136, 810-828.

Provenza FD, Lynch JJ and Nolan JV 1993. The relative importance of mother and toxicosis in the selection of foods by lambs. Journal of Chemical Ecology 19, 313-323.

Provenza FD, Villalba JJ, Cheney CD and Werner SJ 1998. Self-organization of foraging behavior: from simplicity to complexity without goals. Nutrition Research Reviews 11, 199-222.

Provenza FD, Burritt EA, Perevolotsky A and Silanikove N 2000. Self-regulation of intake of polyethylene glycol by sheep fed diets varying in tannin concentrations. Journal of Animal Science 78, 1206-1212.

Provenza FD, Villalba JJ, Dziba LE, Atwood SB and Banner RE 2003. Linking herbivore experience, varied diets, and plant biochemical diversity. Small Ruminant Research 49, 257-274. 
Provenza FD, Villalba JJ, Haskell J, MacAdam JW, Griggs TC and Wiedmeier RD, 2007. The value to herbivores of plant physical and chemical diversity in time and space. Crop Science 47, 382-398.

Raubenheimer D and Simpson SJ 1997. Integrative models of nutrient balancing: application to insects and vertebrates. Nutrition Research Reviews 10, 151-179.

Richter CP 1936. Increased salt appetite in adrenalectomized rats. American Journal of Physiology 115, 155-161.

Robles M, Arguellin M, West J and Rodriguez E 1995. Recent studies on zoopharmacognosy, pharmacology and neurotoxicology of sesquiterpene lactones. Planta Medica 61, 199-203.

Rodriguez E and Wrangham R 1993. Zoopharmacognosy: the use of medicinal plants by animals. In Recent advances in phytochemistry. Phystochemical potential of tropical plants (ed. KR Downum, JT Romeo and HA Stafford), vol. 27, pp. 89-105. Plenum Press, New York, NY, USA.

Rose E 1998. Lifelines. Biology beyond determinism. Oxford University Press, Oxford, UK.

Rosenthal GA and Janzen DH 1979. Herbivores: their interaction with secondary plant metabolites. Academic Press, New York, NY, USA.

Rozin P 1976. Curt Richter: the compleat psychobiologist. In The psychobiology of Curt Richter. York Press Inc., Baltimore, MD, USA.

Schmidt-Nielsen K 1994. How are control systems controlled? American Scientist 82, 38-44.

Schulkin J 2001. Calcium hunger. Behavioral and biological regulation. Cambridge University Press, Cambridge, UK.

Schulkin J 2005. Curt Richter: a life in the laboratory. The Johns Hopkins University Press, Baltimore, MD, USA.

Simpson SJ and Raubenheimer D 1999. Assuaging nutritional complexity: a geometrical approach. Proceedings of the Nutrition Society 58, 779-789.

Skinner BF 1981. Selection by consequences. Science 213, 501-504.

Skinner BF 1984. The evolution of behavior. Journal of the Experimental Analysis of Behavior 41, 217-221.

Stephens DW and Krebs JR 1986. Foraging theory. Princeton University Press, Princeton, NJ, USA.

Strong L 1993. Overview: the impact of ivermectins on pastureland ecology. Veterinary Parasitology 48, 3-17.

Villalba JJ and Provenza FD 1996. Preference for flavored wheat straw by lambs conditioned with intraruminal administrations of sodium propionate. Journal of Animal Science 74, 2362-2368.
Villalba JJ and Provenza FD 1997a. Preference for wheat straw by lambs conditioned with intraruminal infusions of starch. British Journal of Nutrition 77, 287-297.

Villalba JJ and Provenza FD 1997b. Preference for flavored foods by lambs conditioned with intraruminal administrations of nitrogen. British Journal of Nutrition 78, 545-561.

Villalba JJ and Provenza FD 1997c. Preference for flavored wheat straw by lambs conditioned with intraruminal infusions of acetate and propionate. Journal of Animal Science 75, 2905-2914.

Villalba JJ and Provenza FD 1999. Nutrient-specific preferences by lambs conditioned with intraruminal infusions of starch, casein, and water. Journal of Animal Science 77, 378-387.

Villalba JJ and Provenza FD 2000. Postingestive feedback from starch influences the ingestive behaviour of sheep consuming wheat straw. Applied Animal Behaviour Science 66, 49-63.

Villalba JJ and Provenza FD 2001. Preference for polyethylene glycol by sheep fed a quebracho tannin diet. Journal of Animal Science 79, 2066-2074.

Villalba JJ and Provenza FD 2002. Polyethylene glycol influences selection of foraging location by sheep consuming quebracho tannin. Journal of Animal Science 80, 1846-1851.

Villalba JJ, Provenza FD and Han G 2004. Experience influences diet mixing by herbivores: implications for plant biochemical diversity. Oikos 107, 100-109.

Villalba JJ, Provenza FD, Hall JO and Peterson C 2006a. Phosphorous appetite in sheep: dissociating taste from postingestive effects. Journal of Animal Science 84, 2213-2223.

Villalba JJ, Provenza FD and Shaw $R$ 2006b. Sheep self-medicate when challenged with illness-inducing foods. Animal Behaviour 71, 1131-1139.

Vitazkova SK, Long E, Paul A and Glendinning JI 2001. Mice suppress malaria infection by sampling a 'bitter' chemotherapy agent. Animal Behaviour 61, 887-894.

Waghorn GC and McNabb WC 2003. Consequences of plant phenolics compounds for productivity and health of ruminants. Proceedings of the Nutrition Society 62, 383-392.

Waller PJ 2006. Sustainable nematode parasite control strategies for ruminant livestock by grazing management and biological control. Animal Feed Science and Technology 126, 277-289.

Westoby M 1978. What are the biological bases of varied diets? American Naturalist 112, 627-631. 